\title{
Photosynthesis and growth kinetics of Chlorella vulgaris R-117 cultured in an internally LED-illuminated photobioreactor
}

\author{
J.R. MALAPASCUA ${ }^{*, * *}$ K. RANGLOVÁ*, ${ }^{* * *}$, and J. MASOJÍDEK ${ }^{* * *,+}$ \\ Centre ALGATECH, Laboratory of Algal Biotechnology, Institute of Microbiology, Czech Academy of Science, \\ 37981 Třeboň, Czech Republic* \\ Faculty of Science, University of South Bohemia, České Budějovice, Czech Republic** \\ Faculty of Agriculture, University of South Bohemia, České Budějovice, Czech Republic***
}

\begin{abstract}
The aim of this work was to correlate changes of photosynthesis activity vs. growth in Chlorella vulgaris R-117 (CCALA 1107), fast-growing and robust microalga cultured in an internally illuminated 10-L photobioreactor (PBR). The cultures were grown at high output irradiance provided by four LED light sources submerged in the culture when the light path was short, between 25-30 mm. The culture of Chlorella R-117 grown under 2,500 $\mu$ mol(photon) $\mathrm{m}^{-2} \mathrm{~s}^{-1}$ attained a doubling time of $3.5 \mathrm{~d}$ and biomass density of $3.5 \mathrm{~g}(\mathrm{DM}) \mathrm{L}^{-1}$ after about $10-\mathrm{d}$ period. When grown under $3,500 \mu \mathrm{mol}(\mathrm{photon})$ $\mathrm{m}^{-2} \mathrm{~s}^{-1}$, the culture reached a doubling time of $1.7 \mathrm{~d}$, and biomass density of $\sim 5.5 \mathrm{~g} \mathrm{~L}^{-1}$ before entering the stationary phase. Electron transport rate changes correlated well with the culture growth demonstrating the usefulness of chlorophyll fluorescence for photosynthesis monitoring. This can be crucial for potential scale-up to large indoor PBRs to optimise culture growth.
\end{abstract}

Additional key words: chlorophyll fluorescence; light-response curves; microalgae; OJIP induction kinetics; pigments.

\section{Introduction}

Dense, well-mixed culture of microalgae [ $>0.5 \mathrm{~g}$ (biomass) $\mathrm{L}^{-1}$ ] with sufficient nutrition and gas exchange is completely different from optically thin natural phytoplankton populations. In principle, two basic approaches are used to grow microalgae mass cultures: the first applies to growth in 'open' reservoirs, while the second represents 'closed' systems - photobioreactors (PBRs, closed or semiclosed vessels with no direct contact between the culture and atmosphere). A variety of PBRs - using either natural or artificial illumination - have been designed to grow microalgae mass cultures phototrophically. These can consist of glass or transparent plastic tubes, columns or panels, positioned horizontally or vertically, arranged as serpentine loops, fences, flexible coils, or as a series of panels or columns in which the microalgae suspension is continuously mixed or circulated (for a review see e.g. Tredici 2004, Carvalho et al. 2006, Zittelli et al. 2013, Masojídek et al. 2015, Sergejevová et al. 2015, Acién et al. 2017).

PBRs can be illuminated naturally or using artificial light sources. The latter - filament bulbs, fluorescent tubes or high-intensity discharge lamps (pressure sodium lamps) - have been used in indoor PBRs since the early days of microalgae biotechnology (for an overview see Pulz et al. 2013). In order to reduce the loss of light and to increase efficiency of artificial lighting, PBRs with internal illumination have been designed for microalgae culturing (e.g. Radmer 1989, Hirata et al. 1996, Ogbonna et al. 1996, 1999; An and Kim 2000, Csögör et al. 2001, Suh and Lee 2001, Gordon 2002, Chen and Chang 2006, Chen et al. 2006a,b, 2008; Chiang et al. 2011, Choi et al. 2011, Wang et al. 2014, Sergejevová et al. 2015). Moreover, the use of continuous illumination is advantageous since biomass losses due to respiration in diurnal dark periods can be avoided. One important point is to optimize illumination intensity, light path, and effective mixing to supply cells with light and nutrients evenly and facilitate efficient gas exchange.

Starting in the 1990s, novel light sources light-emitting diodes (LED) - have been employed in laboratory panel or column PBRs for microalgae growth (e.g. Lee and Palsson 1994, 1995, Nedbal et al. 1996,

$\overline{\text { Received }} 26$ February 2018, accepted 16 August 2018.

${ }^{+}$Corresponding author; phone:(+420) 384340460, fax: (+420) 384340415 , email: masojidekj@seznam.cz, masojidek@alga.cz Abbreviations: Car - carotenoid; Chl - chlorophyll; DM - dry mass; E - irradiance; $\mathrm{F}_{0}, \mathrm{~F}_{\mathrm{v}}, \mathrm{F}_{\mathrm{m}}-$ minimal, variable, and maximal fluorescence in dark-adapted state; $F^{\prime}, F_{m}{ }^{\prime}-$ steady-state and maximal fluorescence in light-adapted state; $F_{v} / F_{m}, \Delta F^{\prime} / F_{m}{ }^{\prime}-$ maximal, resp. actual photochemical yield of PSII; L/D cycle - light-dark cycle; LED - light-emitting diode; LED-PBR-10 - 10-L photobioreactor illuminated by light-emitting diodes; OD - optical density; OJIP curve - fast Chl fluorescence induction kinetics; P - biomass productivity; PAM - pulse-amplitude modulation; PBR - photobioreactor; rETR - relative electron transport rate through PSII; RLC rapid light-response curve.

Acknowledgements: The authors thank Mr. Pavel Souček and Ms. Soňa Pekařová for technical assistance and Dr. Magda Sergejevová for discussion of results. This study was supported by the Ministry of Education, Youth and Sports, National Sustainability Programme (project Algatech Plus LO1416) and by EU programme Horizon 2020 (project SABANA, grant no.727874). 
2012, Cuaresma et al. 2009, Jacobi et al. 2012). Since, LED technology has been continuously improved over the last decade. In comparison to other lighting systems, LEDs have relatively low construction and operational costs, can operate with low electrical voltage and current, and due to its miniature size, can be easily fitted into any PBR design (Yam and Hassan 2005). The application of LEDs in PBRs represents a great advantage over existing indoor lighting as it allows the grower to control the light intensity (and frequency) in optimizing illumination.

In microalgae cultivation, the use of some monitoring technique (oxygen production, fluorescence) is advantageous to provide rapid and real-time control of culture physiological status (Havlik et al. 2013). When growing, microalgae cells change their photosynthetic activity according and hence this is a good indicator of growth (Malapascua et al. 2014). Since the mid-1980s chlorophyll (Chl) fluorescence has been used in assessing photosynthesis and physiological changes of microalgae mass cultures in various PBRs (Walker 1985, Schreiber et al. 1986, Vonshak et al. 1994, Torzillo et al. 1996, 1998; Figueroa et al. 1997, 2013; Maxwell and Johnson 2000, Kromkamp and Foster 2003, Ralph and Gademann 2005, Bischof et al. 2006, Obata et al. 2009, Masojídek et al. 2011a, White et al. 2011, Malapascua et al. 2014). One of the commonly used fluorescence techniques, pulseamplitude-modulation (PAM), gives information on the balance between photosynthetic electron transport chain, dissipation of absorbed energy and the Calvin-Benson cycle. The so-called rapid light-response curves (RLC) of relative electron transport (rETR) show the dependency of photosynthesis on the irradiance intensity (e.g. Kromkamp et al. 1998, Ralph and Gademann 2005, Enríquez and Borowitzka 2010, Malapascua et al. 2014). It can be used to estimate photosynthetic performance and growth of microalgae cultures (Malapascua et al. 2014). The other approach is to examine fast fluorescence induction kinetics characterized by the so-called OJIP curve that provides information on the activity of the acceptor side of PSII and other partial electron transport events and the effective antenna size (Strasser et al. 2004, Ritchie 2008, Stirbet and Govindjee 2011).

In the present study, we correlated growth kinetics and photosynthesis changes (using Chl fluorescence monitoring techniques) of the microalga Chlorella vulgaris, strain $\mathrm{R}-117$, in a column photobioreactor with high-intensity internal LED light sources submerged directly into culture. This is beneficial for potential scale-up to large indoor PBRs where monitoring of photosynthetic performance of microalgae cultures can be crucial to optimise growth.

\section{Materials and methods}

Strains and culture conditions: The fast-growing and robust microalga Chlorella vulgaris, strain R-117 (CCALA 1107; Culture Collection of Autotrophic Organisms, Institute of Botany, Třeboň, Czech Republic), further as Chlorella R-117, was cultivated in a modified (double concentrated) inorganic medium, $\mathrm{pH} 7.4$, containing the following compounds (in $\mathrm{g} \mathrm{L}^{-1}$ ): $\mathrm{KNO}_{3}, 4.04 ; \mathrm{KH}_{2} \mathrm{PO}_{4}$,
$0.68 ; \mathrm{MgSO}_{4} \cdot 7 \mathrm{H}_{2} \mathrm{O}, 1.98$, and some other micro- and trace compounds - ferric-sodium chelatonate, $\mathrm{CaCl}_{2}, \mathrm{H}_{3} \mathrm{BO}_{3}$, $\mathrm{MnCl}_{2} \cdot 4 \mathrm{H}_{2} \mathrm{O}, \mathrm{ZnSO}_{4} \cdot 7 \mathrm{H}_{2} \mathrm{O}, \mathrm{CuSO}_{4} \cdot 5 \mathrm{H}_{2} \mathrm{O}, \mathrm{CoSO}_{4} \cdot 7 \mathrm{H}_{2} \mathrm{O}$, $\left(\mathrm{NH}_{4}\right)_{6} \mathrm{Mo}_{7} \mathrm{O}_{24}$, and $\mathrm{NH}_{4} \mathrm{VO}_{3}$ (Šetlík et al. 1972, Zachleder and Setlík 1982, Babaei et al. 2017). This nutrient-rich medium was used in order to maintain sufficient growth up to about $8 \mathrm{~g}$ of biomass per litre (contains about 7-8\% nitrogen and $1-2 \%$ phosphorus). Chlorella R-117 was used in this trial due to its high growth rates and tolerance to high irradiance tested in outdoor cultures (Masojídek et al. 2011b). The light-acclimated stock cultures were grown in 2-L flat Roux bottles which were submerged in temperature-controlled water bath $\left(30^{\circ} \mathrm{C}\right)$, mixed by bubbling air $+1.5 \% \mathrm{CO}_{2}(\mathrm{v} / \mathrm{v})$ and exposed to continuous illumination using day-light fluorescent lamps at an irradiance of about $150-250 \mu \mathrm{mol}$ (photon) $\mathrm{m}^{-2} \mathrm{~s}^{-1}$. For experiments the cells were harvested at mid-logarithmic phase of growth by centrifugation at $2,000 \times g$ for $4 \mathrm{~min}$ and resuspended in the fresh medium.

Photobioreactor with internal LED illumination: A double-jacketed glass column (B. Braun Biotech, Germany) was used as a vertical vessel to set up a model photobioreactor, designated as LED-PBR-10 (Fig.1A). The working volume was about $10 \mathrm{~L}$ (an internal diameter of $190 \mathrm{~mm}$ and a total height of $400 \mathrm{~mm}$ ). The four specially constructed LED sources (see insert in Fig. 1A) were mounted vertically through the lid of the PBR and submerged in microalgae culture. To provide uniform illumination, the light sources were arranged $25 \mathrm{~mm}$ apart inside the PBR and $\sim 30 \mathrm{~mm}$ from the inner wall (Fig. 1B). Each of the internal light sources (with a total power input of either $2 \times 35 \mathrm{~W}+2 \times 80 \mathrm{~W}$, or $4 \times 80 \mathrm{~W}$ ) was made of a rectangular aluminium rod $(500 \mathrm{~mm}$ long, $10 \times 10 \mathrm{~mm}$ profile) with a $300-\mathrm{mm}$ long LED strips fastened along all four sides. The LED holder was then inserted into a glass tube (inner diameter of $37 \mathrm{~mm}$ ) with a closed bottom end. Two types of LED strips - neutralwhite and warm-white were combined (see an insert in Fig. $1 A$ ). In this arrangement all light was evenly dispersed in the microalgae suspension. Irradiance intensity could be adjusted using a voltage regulator. In cultivation trials continuous illumination was provided either of about $2,500 \mu \mathrm{mol}$ (photon) $\mathrm{m}^{-2} \mathrm{~s}^{-1}$ (Trial A) or of about 3,500 $\mu \mathrm{mol}\left(\right.$ photon) $\mathrm{m}^{-2} \mathrm{~s}^{-1}$ (Trial B). Important to note that these high light intensities (PAR) were measured directly at the outer surface submerged in water.

The production of heat by LEDs was rather low; necessary cooling of the light sources was maintained by heat exchange with microalgae culture which was controlled through the double jacket of the cultivation vessel connected to a thermo-regulated water circulation system. A stream of filtered air $\left(+1.5 \% \mathrm{CO}_{2}\right)$ was bubbled from a stainless steel loop with evenly-spaced perforations (0.5 mm, $10 \mathrm{~mm}$ apart) placed at the vessel bottom maintaining mixing, sufficient supply of nutrients and the removal of oxygen produced via photosynthesis. Additionally, magnetic bar mixing can guarantee sufficient turbulence to maintain averaged cell irradiance. In this way, short light-dark cycles are produced which are crucial for 

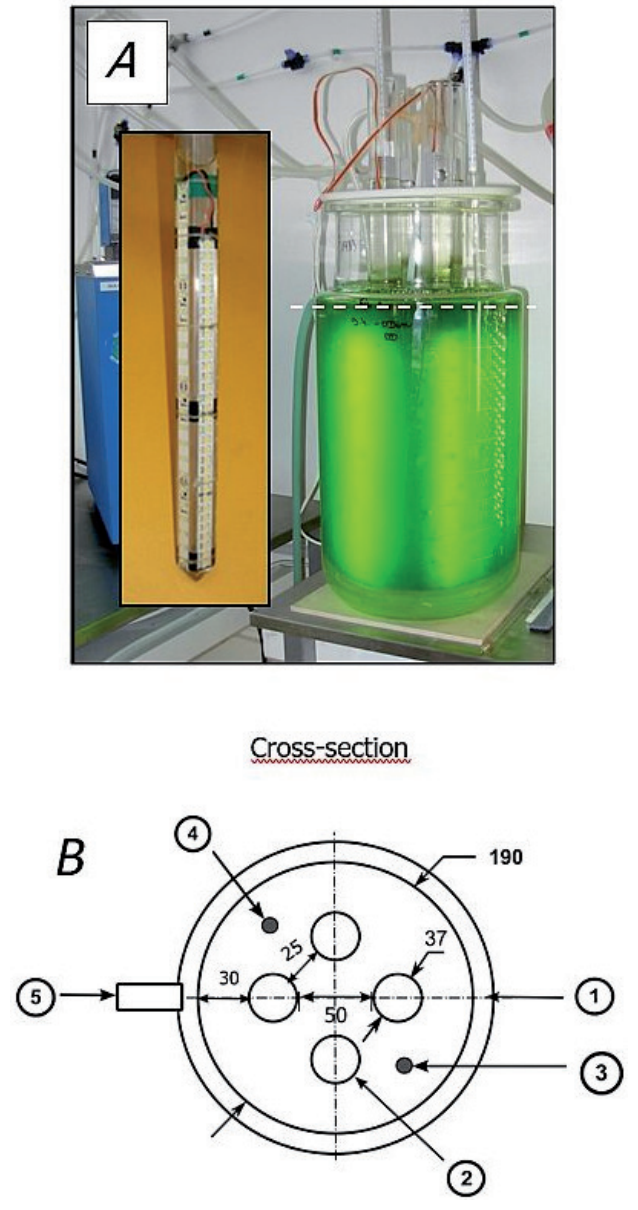

Fig. 1. (A) Column photobioreactor, LED-PBR-10 with internal illumination used in trials. The PBR consists of a doublejacketed, glass column (with a working volume of $8 \mathrm{~L}$ ) and a total height of $400 \mathrm{~mm}$. (Insert: Image of one of four tubular light LED sources that were submerged in the microalgae culture. Neutral-white and warm-white, high intensity LED strips (300 $\mathrm{mm}$ long) were evenly combined and glued along all four sides of a rectangular aluminium rod; the holder was then inserted into a glass tube of inner diameter of $37 \mathrm{~mm}$ with a closed bottom end.). (B) Cross-sectional view of a lid of the PBR with an internal diameter of $190 \mathrm{~mm}(1)$, in which four tubular light sources are mounted and submerged to microalgae culture (2). The stream of filtered air (containing $1.5 \% \mathrm{CO}_{2}$ ) is supplied by a loop (3) to mix and supply $\mathrm{CO}_{2}$ to cells and remove oxygen produced in photosynthesis (4). The temperature is controlled via the water circuit of a temperature controller connected to a double-jacket (5) of the cultivation vessel.

high photosynthetic activity (Zarmi et al. 2013). A slight overpressure inside the cultivation vessel was maintained $(\sim 10 \mathrm{kPa})$ that prevented microalgae culture from external contamination. All inputs for medium, air supply and temperature and $\mathrm{pH}$ sensors were piped through the lid of the PBR. The thickness of photic microalgae layer (light path) varied between 25 and $30 \mathrm{~mm}$.

Growth and pigment analyses: Biomass density was measured as dry mass (DM) by filtering $5 \mathrm{ml}$ of culture samples to preweighed fibre-glass filters $(G C-50)$, which were dried in an oven at $105^{\circ} \mathrm{C}$ for $3 \mathrm{~h}$ and then transferred to a desiccator to equilibrate at laboratory temperature and weighed. The growth rate $\left[\mu=\left(\ln \mathrm{X}_{2}-\ln \mathrm{X}_{1}\right) / \Delta \mathrm{t} ; \mathrm{d}^{-1}\right]$ and doubling time $\left(t_{D}=\ln 2 / \mu ; d\right)$ of the culture were calculated.

The content of total Chls and carotenoids (Car) was determined in $80 \%$ acetone by breaking microalgae cells by intensive abrasion with glass beads using a vortex mixer for $2 \mathrm{~min}$. The supernatant containing pigments was collected after centrifugation. If necessary, the extraction was repeated several times until the pellet was clear of pigments. The absorbance of the combined supernatants of all extraction steps was measured using a high resolution spectrophotometer (UV 2600 UV-VIS, Shimadzu, Japan; slit width of $0.5 \mathrm{~nm}$ ) and the concentrations of pigments were calculated according to Wellburn (1994).

Nutrient analysis: Content of nutrients (nitrate, sulphate, and phosphate) in the culture medium were analysed during trials using an ion chromatography system (ICS-90, Dionex fitted with an AS22-Fast $4 \times 150 \mathrm{~mm}$, Dionex IonPac ${ }^{T M}$ column). The samples were diluted twice with deionized water and $10-\mu \mathrm{L}$ aliquots were used for the analysis. The solutions of $1.4 \mathrm{mM} \mathrm{NaHCO}_{3}$ and $4.5 \mathrm{mM} \mathrm{Na}_{2} \mathrm{CO}_{3}$ were used as mobile phase for isocratic selection of compounds according to charge and molecular dimension. A solution (CZ 9102-IC MIX 22, Analytika, Ltd., Czech Republic) of known anion concentrations was used as standard to construct the calibration curve. Nutrient concentrations were calculated in $\mathrm{mg} \mathrm{L}^{-1}$ and expressed as percentage of the initial concentration ( $\%$ of initial).

Chl fluorescence measurements: Samples were taken from the cultures and measured in triplicates (data presented as mean $\pm \mathrm{SE}$ ) at specific time points. Before measurement, the cultures were diluted to 0.2 to $0.3 \mathrm{~g}(\mathrm{DM})$ $\mathrm{L}^{-1}$ [corresponding to 5 to $7 \mathrm{mg}(\mathrm{Chl}) \mathrm{L}^{-1}$ ] with growth medium, dark-adapted for 5-10 min, and then transferred to measuring chamber. Measurements were carried out under well-defined laboratory conditions with similar 'light' exposure history to avoid modifying the photoacclimation status of the cells. In this way, we prevented re-absorption problems with a dense culture by providing sufficient illumination in the dark-acclimated samples (with an oxidized plastoquinone pool). The fluorescence nomenclature in this paper follows Schreiber et al. (1986) as later elaborated by van Kooten and Snel (1990) and Kromkamp and Foster (2003).

Rapid light-response curves (RLC) of microalgae samples were measured using a pulse-amplitudemodulation fluorimeter (PAM-2500, H. Walz, Germany) in a light-protected measuring chamber with mixing (3-mL glass cuvette, light path of $10 \mathrm{~mm}$ ). A series of stepwise increasing irradiance intensities [red LEDs; 0-2,700 $\mu \mathrm{mol}($ photon $\left.) \mathrm{m}^{-2} \mathrm{~s}^{-1}\right]$ were applied in 20 -s intervals to obtain the steady-state fluorescence level $\mathrm{F}^{\prime}$ in the light-adapted state at respective irradiance level and then a saturating pulse $\left[>10,000 \mu \mathrm{mol}\right.$ (photon) $\mathrm{m}^{-2} \mathrm{~s}^{-1}, 0.6 \mathrm{~s}$ duration] was triggered to reach the $\mathrm{F}_{\mathrm{m}}{ }^{\prime}$, the maximal fluorescence level. At each step the actual PSII photochemical quantum 
yield in the light, $Y_{\mathrm{II}}$ was determined as $\left(\mathrm{F}_{\mathrm{m}}{ }^{\prime}-\mathrm{F}^{\prime}\right) / \mathrm{F}_{\mathrm{m}}{ }^{\prime}$. The minimum and maximal fluorescence level $\left(\mathrm{F}_{\mathrm{o}}, \mathrm{F}_{\mathrm{m}}\right)$ were determined using a weak modulated light $[<0.15$ $\mu$ mol(photon) $\mathrm{m}^{-2} \mathrm{~s}^{-1}$, frequency of $\left.0.5-1 \mathrm{kH}\right]$ in the dark-adapted samples (actinic irradiance $=0$; first step of RLC). The maximal PSII quantum yield was calculated as the ratio of variable and maximal fluorescence, $F_{v} / F_{m}=$ $\left(\mathrm{F}_{\mathrm{m}}-\mathrm{F}_{\mathrm{o}}\right) / \mathrm{F}_{\mathrm{m}}$; it indicates the capacity of the system to absorb light through the reaction centres and the lightharvesting complex and expresses the maximum quantum efficiency of primary photochemistry (Strasser et al. 2004). Analysis of RLC was used to calculate changes in important variables of $\mathrm{rETR}_{\max }$ and nonphotochemical quenching NPQ calculated as $\left(\mathrm{F}_{\mathrm{m}}-\mathrm{F}_{\mathrm{m}}{ }^{\prime}\right) / \mathrm{F}_{\mathrm{m}}{ }^{\prime}$. The variable, called the relative electron transport rate through PSII, rETR, was calculated as multiplication of the actual photochemical efficiency $Y_{\text {II }}$ by the photosynthetically active radiation $\mathrm{E}_{\mathrm{PAR}}, \mathrm{rETR}=\mathrm{Y}_{\mathrm{II}} \times \mathrm{E}_{\mathrm{PAR}}$ [dimensionless as it is called relative] (e.g. Hofstraat et al. 1994, Ralph and Gademann 2005, White et al. 2011). In order to estimate $\mathrm{rETR}_{\max }$, and the irradiance saturating photosynthesis the

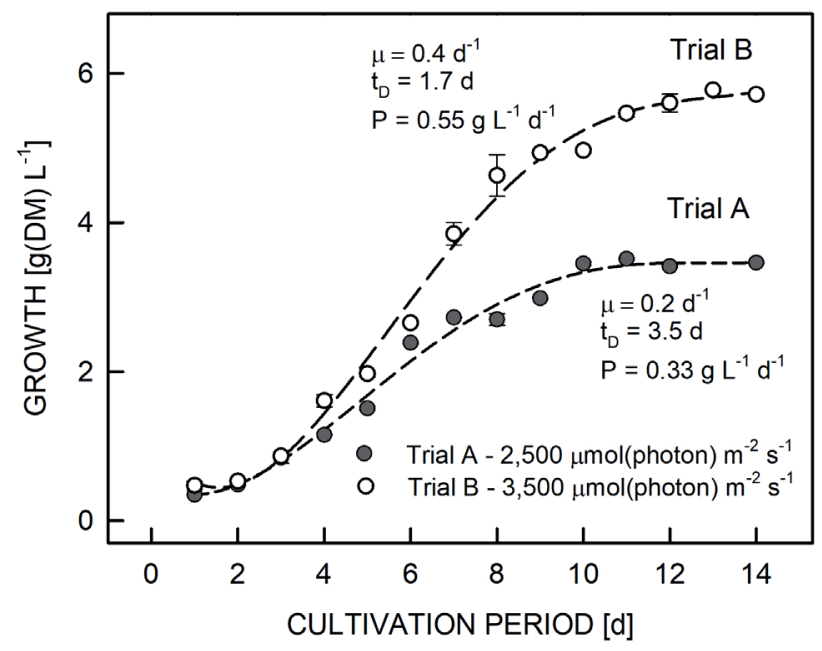

Fig. 2. Growth curves of Chlorella R-117 in the PBR exposed to continuous irradiance of 2,500 $\mu \mathrm{mol}$ (photon) $\mathrm{m}^{-2} \mathrm{~s}^{-1}$ (close symbols), or 3,500 $\mu \mathrm{mol}\left(\right.$ photon) $\mathrm{m}^{-2} \mathrm{~s}^{-1}$ (open symbols). Values are presented as a mean $(n=3)$ with SE indicated by error bars. Broken lines are the fitted curves according to logistic growth model.

rETR vs. irradiance curves were fitted to the non-linear least-squares regression model by Eilers and Peeters (1998) using the Solver function of Excel (Microsoft, Redmond, USA) (Fig. 2).

Fast fluorescence induction kinetics (OJIP-test): A portable modulated fluorimeter (AquaPen AP-100, P.S.I. Ltd., Brno, Czech Republic) adapted for liquid samples was used to follow rapid fluorescence induction kinetics $(\sim 1 \mathrm{~s})$ in microalgae cultures. Dark-adapted samples were pipetted to a measuring cuvette (light path of $10 \mathrm{~mm}$ ) which was mounted in a light-protected holder in front of the detector (adjustable measuring light pulses, $\sim 2.5 \mu \mathrm{s}$ ) while illuminating red LEDs served as high-intensity continuous light from both sides of the cuvette [up to $3,000 \mu \mathrm{mol}$ (photon) $\mathrm{m}^{-2} \mathrm{~s}^{-1}$, perpendicular to the detector. The fast fluorescence induction kinetics was measured in the time range between $50 \mu \mathrm{s}$ to $1 \mathrm{~s}$; it started upon illumination (saturating continuous light) of dark-adapted microalgae culture as the signal increased rapidly from the origin $(\mathrm{O})$ to a peak $(\mathrm{P})$ via two inflections $-\mathrm{J}$ and I (Strasser et al. 1995). The O point of the fluorescence induction curve represents a minimum value (designated as constant fluorescence yield $\mathrm{F}_{0}$ ) when plastoquinone electron acceptors $\left(\mathrm{Q}_{\mathrm{A}}\right.$ and $\left.\mathrm{Q}_{\mathrm{B}}\right)$ of the PSII complex are fully oxidized. It is the signal emitted from excited $\mathrm{Chl} a$ molecules in the light-harvesting complex II before excitons have migrated to the PSII reaction centre. The inflection J occurs after $\sim 2-3 \mathrm{~ms}$ of illumination and reflects a reduction of $\mathrm{Q}_{\mathrm{A}^{-}}$(photochemical phase). The second inflection I occurs some $30-50 \mathrm{~ms}$ after illumination and it is thought to reflect temporary maximum of $\mathrm{Q}_{\mathrm{A}}{ }^{-} \mathrm{Q}_{\mathrm{B}}{ }^{2-}$. The rise of fluorescence from $\mathrm{J}$ to the peak $\mathrm{P}$ represents the thermal phase influenced by the two-step reduction of $\mathrm{Q}_{\mathrm{B}}\left(\mathrm{Q}_{\mathrm{B}} \rightarrow \mathrm{Q}_{\mathrm{B}}{ }^{-} \rightarrow \mathrm{Q}_{\mathrm{B}}{ }^{2-}\right)$, and heterogeneity in the reduction status of plastoquinone pool. Finally, fluorescence yield reaches the peak $\mathrm{P}$ when the $\mathrm{PQ}$ pool becomes fully reduced (equivalent to maximal fluorescence level $\mathrm{F}_{\mathrm{m}}$ ).

Statistical analysis: All measurements were performed three times $(n=3)$ and the means and calculated standard errors (SE) are reported. SigmaPlot 11.0 was used to determine significant differences between treatments. One-way analysis of variance (ANOVA) and Post-Hoc test was conducted for comparison of variables in trials. $P$ values lower than $0.05(P<0.05)$ were considered to be significantly different.

\section{Results}

In order to test the photosynthetic performance of Chlorella R-117 in the LED-PBR-10, the light-adapted cultures were transferred to the fresh medium at a biomass concentration of about $0.4-0.5 \mathrm{~g} \mathrm{~L}^{-1}$ and exposed to high irradiance intensities similar to those occurring outdoors. For the first $24 \mathrm{~h}$ (Day 0), the cultures were exposed to an irradiance intensity of $1,200-1,500 \mu \mathrm{mol}$ (photon) $\mathrm{m}^{-2}$ $\mathrm{s}^{-1}$ to photo-acclimate (measured on the surface of light sources). Close to the wall of the PBR, it was about 150-200 $\mu \mathrm{mol}$ (photon) $\mathrm{m}^{-2} \mathrm{~s}^{-1}$ and about 200-400 $\mu \mathrm{mol}$ (photon) $\mathrm{m}^{-2} \mathrm{~s}^{-1}$ (measured with spherical light sensor) between light sources, when $0.4-0.5 \mathrm{~g}$ culture was grown. Then, two series of experiments were carried out. There was a certain lag-phase period as a response of diluted culture to increased irradiance on Day 0 (Fig. 2), but the cultures were not severely photoinhibited and could quickly overcome - after 1-2 d - the lag phase, even if exposed to high irradiance.

On Day 1, the cultures in Trial A and Trial B received different irradiance treatment; therefore, their behaviour was different. In Trial $\mathrm{A}$, the microalgae cultures were grown at an irradiance of 2,500 $\mu$ mol(photon) $\mathrm{m}^{-2} \mathrm{~s}^{-1}$ (Fig. 2; curve with close circles). At the end of the culti- 
vation period, the culture attained a doubling time of $3.5 \mathrm{~d}\left[\mu=0.2\right.$ day $\left.^{-1}, \mathrm{P}=0.33 \mathrm{~g}(\mathrm{DM}) \mathrm{L}^{-1} \mathrm{~d}^{-1}\right]$ and reached the biomass concentration of $3.4 \mathrm{~g}(\mathrm{DM}) \mathrm{L}^{-1}$. The exponential phase of growth was found between Day 3 and Day 9 (see comment above) when the biomass density was between $0.5-3.0 \mathrm{~g}(\mathrm{DM}) \mathrm{L}^{-1}$; then the culture showed the decelerating phase and reached the stationary phase after $10 \mathrm{~d}$ of the trial.

In the second series of cultivation experiments - Trial B, the irradiance was set to $3,500 \mu \mathrm{mol}$ (photon) $\mathrm{m}^{-2} \mathrm{~s}^{-1}$. The culture showed a doubling time of $1.7 \mathrm{~d}$, the growth rate $\mu$ of 0.4 per day and biomass productivity $\mathrm{P}=0.55 \mathrm{~g}(\mathrm{DM})$ $\mathrm{L}^{-1} \mathrm{~d}^{-1}$. It reached the maximal biomass density of 5.8 $\mathrm{g}(\mathrm{DM}) \mathrm{L}^{-1}$ (Fig. 2; curve with open circles) which was by $66 \%$ higher than that in Trial A. Also in this case, the exponential phase of growth was found between Day 3 and 9 when the biomass density ranged between 0.75 and 5.0 $\mathrm{g}(\mathrm{DM}) \mathrm{L}^{-1}$. Then the culture, similarly as in Trial A, started to enter the decelerating phase although there were still enough nutrients: $27 \% \mathrm{~N}, 40 \% \mathrm{P}$, and $48 \% \mathrm{~S}$ of the initial amount, respectively (Trial $\mathrm{B}$ in Fig. 1S, supplement). According to experimental setup, the medium contained

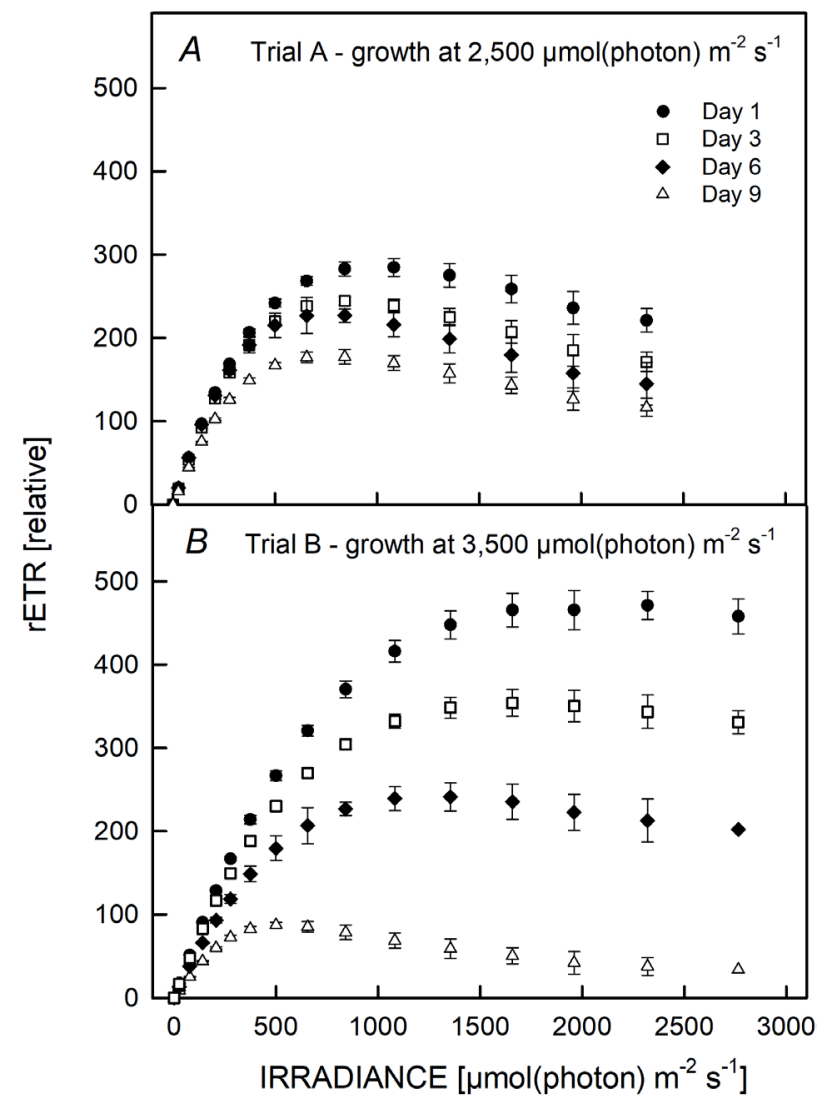

Fig. 3. Rapid light-response curves (RLCs) of the relative electron transport rate rETR vs. irradiance measured in Chlorella R-117 cultures grown under high irradiance $[A-2,500 \mu \mathrm{mol}($ photon) $\left.\mathrm{m}^{-2} \mathrm{~s}^{-1}\right]$ and $\left[B-3,500 \mu \operatorname{mol}\left(\right.\right.$ photon) $\left.\mathrm{m}^{-2} \mathrm{~s}^{-1}\right]$ recorded on Days $1,3,6$, and 9. $\mathrm{rETR}=\mathrm{Y}_{\mathrm{II}} \times \mathrm{E}_{\mathrm{PAR}}$, where $\mathrm{Y}_{\mathrm{II}}$ is the actual photochemical yield of PSII and $E_{\text {PAR }}$ is photosynthetically active radiation. Values are presented as a mean $(n=3)$ with SE indicated by error bars. about $0.55 \mathrm{~g}$ of nitrogen and $0.16 \mathrm{~g}$ phosphorus per litre which should be sufficient for growth of about $8 \mathrm{~g}(\mathrm{DM})$ $\mathrm{L}^{-1}$ (biomass contains about $7-8 \%$ nitrogen and 1-2\% phosphorus). On Day 9 (beginning of the stationary growth phase), the nutrients were still sufficient in both trials as there was still about $43-64 \%$ and $27-47 \%$ of the initial nutrient concentrations in Trial A and Trial B, respectively (Fig. 1S). Then, it implies that the lack of nutrients was not the main reason of photosynthetic activity and the slow-down of growth, but it was due to the decreased light availability and shade adaptation as the cultures were getting denser (Figs. 2, $4 A$ vs. Fig. 1S). After all, in Trial B, in higher-irradiance culture, the growth rate was doubled as compared to the lower-irradiance culture in Trial A.

The growth kinetics in the cultures was reflected by changes of photosynthetic activities that significantly varied between Trial $\mathrm{A}\left[\sim 2,500 \mu \mathrm{mol}\right.$ (photon) $\left.\mathrm{m}^{-2} \mathrm{~s}^{-1}\right]$ and Trial $\mathrm{B}\left[\sim 3,500 \mu \mathrm{mol}\left(\right.\right.$ photon) $\left.\mathrm{m}^{-2} \mathrm{~s}^{-1}\right]$. Generally, in Trial A, rETR was much lower as compared to culture in Trial B. Rapid light-response curves RLC (measured by $\mathrm{Chl}$ fluorescence quenching technique) showed that maximal rETR activities at the beginning of treatment (Day 1-Day 3) were much higher, between 350 and 470 in Trial B $\left[3,500 \mu \mathrm{mol}\right.$ (photon) $\left.\mathrm{m}^{-2} \mathrm{~s}^{-1}\right]$ as compared to the values between 240 and 280 found in Trial A [2,500 $\mu \mathrm{mol}\left(\right.$ photon) $\mathrm{m}^{-2} \mathrm{~s}^{-1}$ ] (Fig. 3). Important to note that in Trial B, the $\mathrm{rETR}_{\max }$ values decreased significantly during the experiment and finally at Day 9 they were lower than these in Trial A. This trend can be explained if we correlate the rETR curves with the growth kinetics; the cultures in Trial B were growing dense and evidently became lowlight-adapted as compared to those in Trial A (Fig. 2 vs. Fig. 3).

The photosynthetic variables calculated from the RLC of the cultures in both trials changed over time. The maximal PSII quantum yield $\left(\mathrm{F}_{\mathrm{v}} / \mathrm{F}_{\mathrm{m}}\right)$ of the cultures in both trials showed a continuous decline regardless of the growth conditions. However, relatively high $F_{v} / F_{m}$ ratio was observed at the start (between 0.75 in Trial $\mathrm{A}$ and 0.71 in Trial B) showing that the cultures were in good physiological conditions. During the two-week experiments, $F_{v} / F_{m}$ showed a decreasing trend in Trial A while in Trial B it declined significantly by about $24 \%$ (Fig. 4A). In Trial $\mathrm{B}$, in the cultures grown at high light intensity, the reduction in the maximum suggested that the culture in Trial B was slightly more tensed as compared that in Trial A.

It is worth noting that maximal relative electron transport rate $\mathrm{rETR}_{\max }$ (Fig. $4 B$ ) and the onset of light saturation $\mathrm{E}_{\mathrm{K}}$ (Fig. $5 A$ ) of the cultures in Trial $\mathrm{B}$ (higher irradiance culture) were significantly higher (by 30-40\%) during Day 1-3 as compared to cultures grown in Trial A (low irradiance culture). Then, later on Day 6, the situation was reversed when the cultures reached the decelerating phase as the culture in Trial A was thinner than that in Trial B (Fig. 2), thus the cells received more light as also confirmed by higher $\mathrm{E}_{\mathrm{K}}$ (Fig. $5 A$ ). Consequently, the $\mathrm{rETR}_{\max }$ values on Day 9 were slightly lower in Trial B compared to that in Trial A (Fig. 4B). Statistically, the decrease of $\mathrm{F}_{\mathrm{v}} / \mathrm{F}_{\mathrm{m}}, \mathrm{rETR}_{\max }$, and $\mathrm{E}_{\mathrm{k}}$ was more significant in 


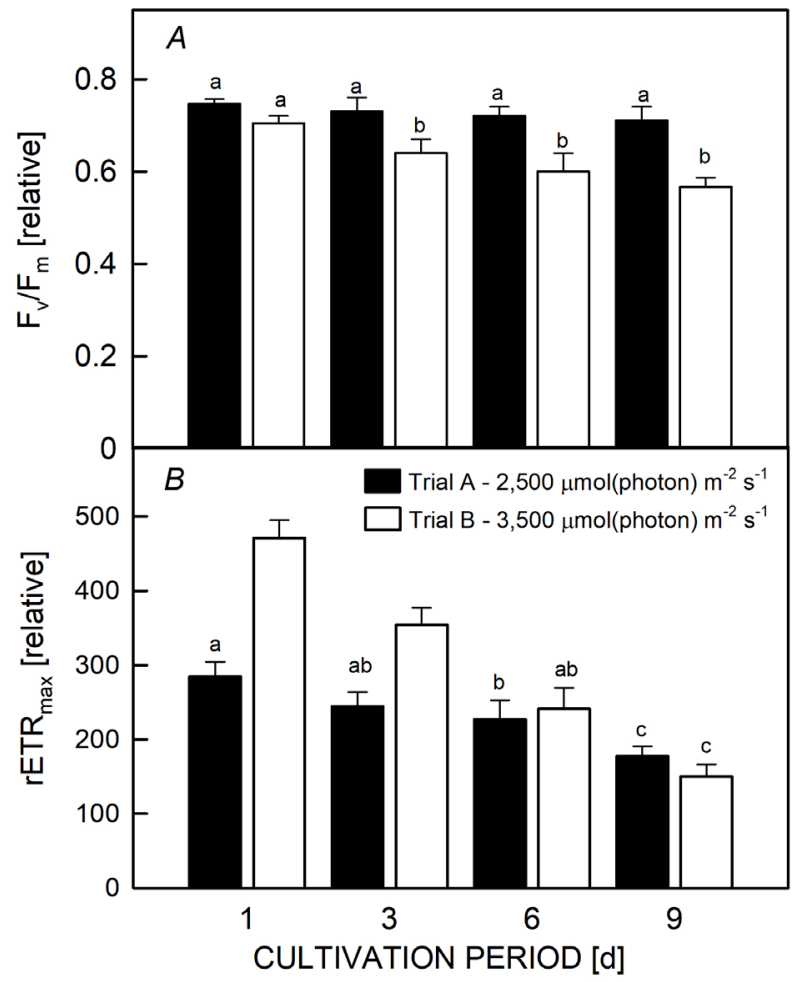

Fig. 4. Changes in the maximum effective quantum yield of PSII $\left(\mathrm{F}_{\mathrm{v}} / \mathrm{F}_{\mathrm{m}}\right)(A)$ and maximum relative electron transport rate $\left(\mathrm{rETR}_{\max }\right)(B)$, of Chlorella R-117 exposed to continuous illumination of $\sim 2,500 \mu \mathrm{mol}$ (photon) $\mathrm{m}^{-2} \mathrm{~s}^{-1}$ (black column) and $\sim 3,500 \mu \mathrm{mol}$ (photon) $\mathrm{m}^{-2} \mathrm{~s}^{-1}$ (grey column) during the 14-day cultivation period. Values are presented as a mean $(n=3)$ with SE indicated by error bars. The mean values designated by the same letter did not differ significantly from each other.

Trial B as compared to Trial A. NPQ indicating dissipation of absorbed light energy showed somehow similar trend to that of rETR. NPQ response of both cultures was partially different as the values in Trial A showed slightly decreasing trend during the experiment, while the NPQ values in Trial $B$ were not much varying. No dramatic increase of NPQ was found which may suggest that the cultures were not as much constrained as only a part of absorbed energy was dissipated as heat (Figs. $4 B, 5 B$ ).

The cultures were further examined in detail to explain significant changes in photochemical performance which started in the stationary phase of growth during the second week of experiments. The contents of photosynthetic pigments of the cultures in both trials were estimated to determine whether the increased irradiance imposes some photo-stress (Fig. 2S, supplement). The total Chl (reaching the maximum of $\sim 2.5 \% \mathrm{DM}$, i.e. about $25 \mathrm{mg}$ $\mathrm{L}^{-1}$ ) and total carotenoid (max. $\sim 0.5 \% \mathrm{DM}$, i.e. $5 \mathrm{mg}$ $\mathrm{L}^{-1}$ ) contents increased from Day 1 and peaked at Day 9, which coincided with the end of the exponential growth phase (Fig. 3) and a significant decrease of $\mathrm{rETR}_{\max }$ (Fig. 4B). The trends were very similar in Trials A and B. The changes in the Chl content of Chlorella R-117 examined in this experiment did not indicate stress imposed by high irradiance as there was no considerable

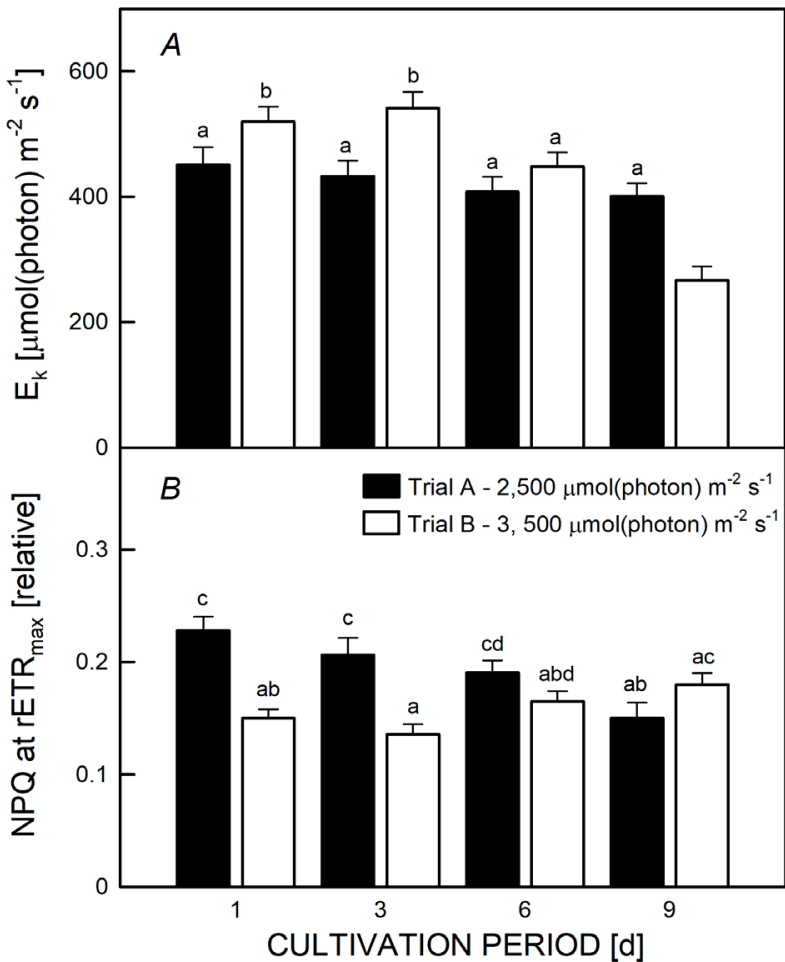

Fig. 5. Changes in the onset of light saturation $\mathrm{E}_{\mathrm{K}}(A)$ and nonphotochemical quenching NPQ $(B)$ of Chlorella R-117 exposed to continuous illumination of $\sim 2,500 \mu \mathrm{mol}$ (photon) $\mathrm{m}^{-2}$ $\mathrm{s}^{-1}$ (black column) and $\sim 3,500 \mu \mathrm{mol}$ (photon) $\mathrm{m}^{-2} \mathrm{~s}^{-1}$ (grey column) during the 14-day cultivation period. Values are presented as a mean $(n=3)$ with SE indicated by error bars. The mean values designated by the same letter did not differ significantly from each other.

increase in the content of photoprotective Car during the first week of cultivation. The increase in the total Chl just reflected the (exponential and stationary) phases of the culture and might be slightly higher in Trial A as compared to Trial B (Fig. 2S).

Fast Chl fluorescence induction kinetics (OJIP test) was used to examine changes of photosynthetic performance, i.e. the substantial alterations of electron transport processes (Fig. 6). The shapes of the OJIP curves were significantly changed in the course of Trial B as these depend on the status of the photosynthetic apparatus in the cultivation period (Fig. 6B). The exposure to high irradiance, especially in the second week of the trial, showed that during Trial $\mathrm{B}$, the variables $\mathrm{V}_{\mathrm{j}}$ and $\mathrm{V}_{\mathrm{i}}$ increased by about 50 and $38 \%$, respectively. It indicated partial over-reduction of the electron transport carriers at the acceptor side of the PSII showing that the cultures were not fully photosynthetically competent as the cells have become low-light-adapted (Strasser et al. 1995, 2004). On the contrary no significant changes of the $V_{j}$ and $\mathrm{V}_{\mathrm{i}}$ variables were found in Trial A (Fig. $7 A$ ).

The changes of $V_{j}$ and $V_{i}$ variables may be an indicative of culture health, as they show a degree of electron transport capacity on the donor side, from $Q_{A}$ to $P Q$ pool in parallel with changes in the electron transport capacity 


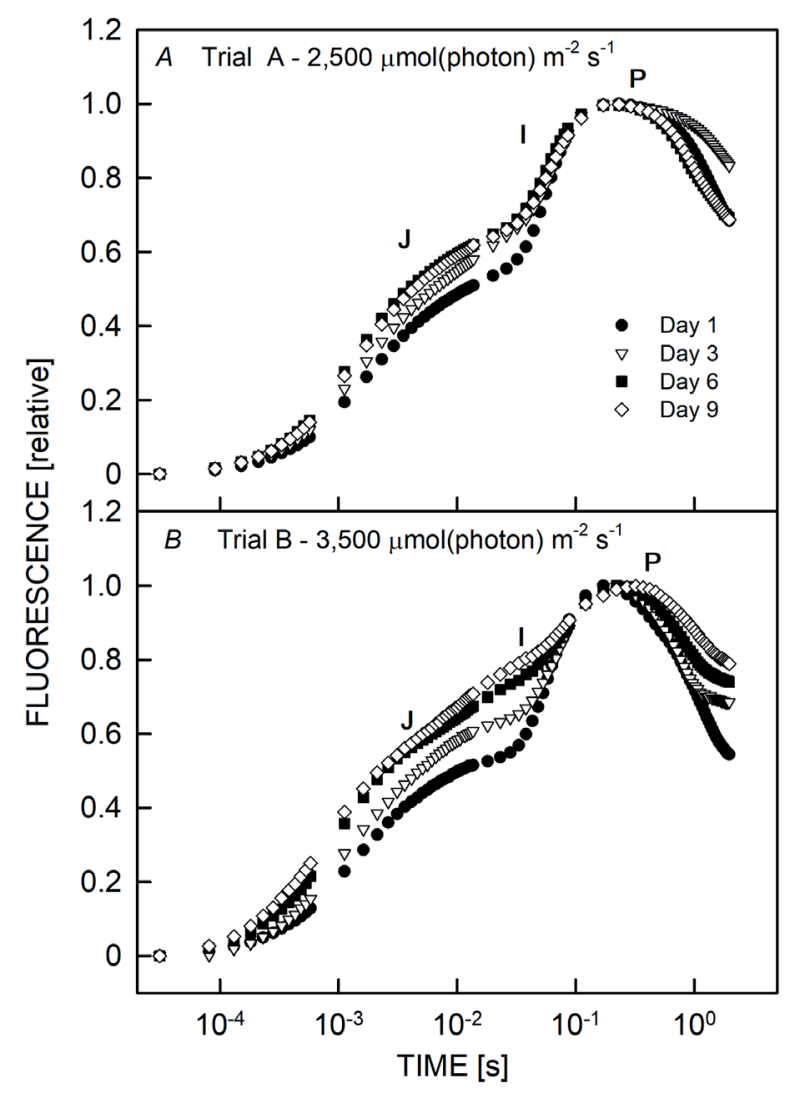

Fig. 6. Changes of rapid Chl fluorescence induction kinetics-OJIP test of Chlorella sp. R-117 grown under continuous illumination of 2,500 $\mu \mathrm{mol}$ (photon) $\mathrm{m}^{-2} \mathrm{~s}^{-1}(A)$ and $3,500 \mu \mathrm{mol}$ (photon) $\mathrm{m}^{-2} \mathrm{~s}^{-1}$ $(B)$ during the 14-day cultivation trial. The OJIP curves were double-normalized to on both $\mathrm{O}\left(\mathrm{F}_{0}\right)$ and $\mathrm{P}\left(\mathrm{F}_{\mathrm{m}}\right)$ to distinguish the differences in the inflections $\mathrm{J}$ and I representing various reduction states of the PSII electron carriers. The curves were recorded in triplicates for each sample and averaged; they consist of different symbols without error bars as these can obscure kinetics if similar.

rETR. However, the increase of in the antenna size can also contribute to these changes since the concentration of $\mathrm{Chl}$ per dry mass was found in both trials (Fig. 2S).

\section{Discussion}

In indoor PBRs, one of the constraints of microalgae cultured at high biomass density, is the efficient delivery of light as growth limitations are mostly caused by a significant reduction of cell irradiance. The use of artificial light sources is advantageous since they can provide continuous illumination preventing biomass losses due to respiration in diurnal dark periods. Compared to conventional, externally illuminated PBRs, those with internal illumination are more energy-efficient since all light is absorbed by the culture. If the conditions are set up properly, the light conversion efficiency and biomass productivity of microalgae cultures can be even higher than that in sunlight. The disadvantages of most

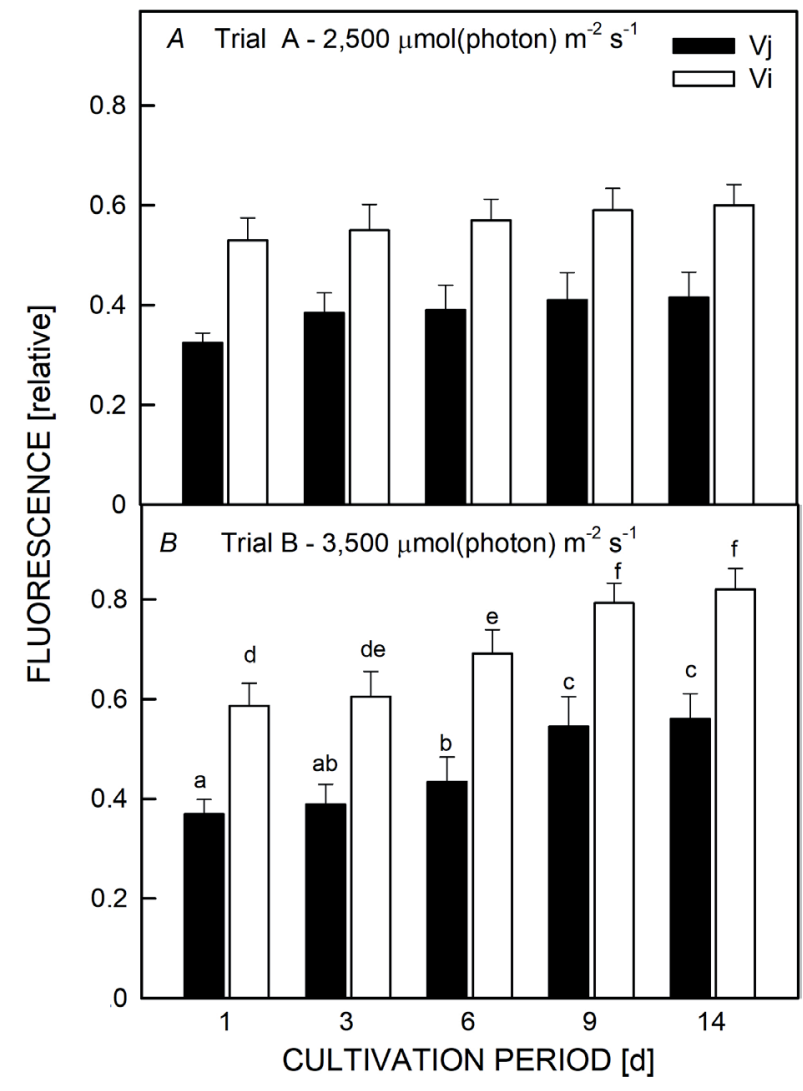

Fig. 7. Changes of the $V_{j}$ and $V_{i}$ variables calculated from fast Chl fluorescence induction kinetics OJIP test of Chlorella sp. R-117 grown under continuous illumination of $2,500 \mu \mathrm{mol}($ photon) $\mathrm{m}^{-2} \mathrm{~s}^{-1}(A)$ and $3,500 \mu \mathrm{mol}$ (photon) $\mathrm{m}^{-2} \mathrm{~s}^{-1}(B)$ during the 14-day cultivation trial. The $\mathrm{V}_{\mathrm{j}}$ and $\mathrm{V}_{\mathrm{i}}$ variables corresponding to the $\mathrm{J}$ and I inflections were calculated as relative variable fluorescence yield. VJ represents the accumulation of the reduced "primary" acceptor $\mathrm{Q}_{\mathrm{A}^{-}}$, and it is calculated according to the formula $\mathrm{V}_{\mathrm{j}}=\left(\mathrm{F}_{2 \mathrm{~ms}}-\mathrm{F}_{0}\right) /\left(\mathrm{F}_{\mathrm{m}}-\mathrm{F}_{0}\right)$. The $\mathrm{V}_{\mathrm{i}}$ parameter reflects different redox states (e.g. $\mathrm{Q}_{\mathrm{A}} \mathrm{Q}_{\mathrm{B}}{ }^{2-}$ or $\left.\mathrm{Q}_{\mathrm{A}}{ }^{-} \mathrm{Q}_{\mathrm{B}}{ }^{2-}\right)$ and is calculated as $\mathrm{V}_{\mathrm{i}}=$ $\left(\mathrm{F}_{30 \mathrm{~ms}}-\mathrm{F}_{0}\right) /\left(\mathrm{F}_{\mathrm{m}}-\mathrm{F}_{0}\right)$. Values are presented as a mean $(n=3)$ with SE indicated by error bars. The mean values designated by the same small and capital letter did not differ significantly from each other for $\mathrm{V}_{\mathrm{j}}$ and $\mathrm{V}_{\mathrm{i}}$, respectively.

conventional light sources (filament bulbs, fluorescent tubes or discharge lamps) have been overcome by the use of LED light sources as these have high energy to light conversion efficiency, low heat generation, high light intensity and recently also low cost for purchase and electricity consumption.

Generally, higher cell irradiance (up to photosynthesis saturating level) achieved inside the PBR, the higher biomass density (and productivity) can be reached. The ambient light maxima [about 2,000 $\mu \mathrm{mol}$ (photon) $\mathrm{m}^{-2} \mathrm{~s}^{-1}$ ] available for photosynthetic antennae represent an intensity that is roughly 5-10 times higher than that required to saturate growth. In other words, as much as $90 \%$ of the photons captured by the photosynthetic antennae may be dissipated as heat (Masojídek and Torzillo 2008).

The important point in microalgae mass culturing is the balance between biomass density and irradiance intensity, 
light path and effective mixing to achieve sufficient average cell irradiance in order to reach high photosynthetic efficiency and biomass productivity (Masojídek et al. 2004, Richmond 2013, Zarmi et al. 2013, Sergejevová et al. 2015). This is a relevant aspect for scale-up of PBRs with high cell densities. Due to the cell movement between illuminated and dark parts of the PBR volume, the microalgae cells experience the flashing (intermittent) light regime producing short light/dark cycles if the light path is short. Light intermittency of tens to hundreds of milliseconds corresponding to the time scale of the ratelimiting dark reactions of photosynthesis enhances lightuse efficiency and subsequently growth rate as light energy is utilized with maximal efficiency (Phillips and Myers 1954, Grobbelaar et al. 1996, Janssen et al. 2000, Richmond 2013, Zarmi et al. 2013).

In our trials, we tested the novel PBR - a cylindrical vessel with internal LED illumination - for microalgae growth in which high-intensity light sources were placed evenly inside the culture to set up relatively short light path. Previously, various internally irradiated photobioreactors were designed, for example with an integrated solar (e.g. based on light collection by Fresnel lenses and optical fibres) and artificial light sources (metal halide lamps) in which light intensity was around $100 \mu \mathrm{mol}$ (photon) $\mathrm{m}^{-2} \mathrm{~s}^{-1}$ and the culture biomass density reached about $1.2 \mathrm{~g}(\mathrm{DM}) \mathrm{L}^{-1}$ (Ogbonna et al. 1999). As compared to that, the presented LED-PBR-10 described here is technically rather simple as high-intensity LEDs were used for illumination. Thus, light intensities used in our trials were more than one order of magnitude higher and biomass density of microalgae cultures increased several times and the microalgae cells were exposed to high irradiance similar to summer light intensities (or more). In this setup, taking into consideration efficient mixing which can generate short light/dark cycles. Even high output irradiance intensity produced by light sources did not inhibit culture growth if biomass density was sufficient. The growth saturating light intensities for Chlorella R-117 cultures in our experiments were found between 400 and $500 \mu \mathrm{mol}$ (photon) $\mathrm{m}^{-2} \mathrm{~s}^{-1}$ at relatively high biomass densities (Fig. $5 \mathrm{~A}$ ) similarly as those measured in outdoor Chlorella R-117 cultures (Masojídek et al. 2011b). When the starting biomass density was about $0.5 \mathrm{~g} \mathrm{~L}^{-1}$, the culture did show short lag phase at the start of the trial as the seed culture was already high-light acclimated (Fig. 2). Then, the exponential growth was recorded during the first week that was comparable to that of $C$. sorokiniana grown in short light-path panel PBRs (Cuaresma et al. 2009). It is important to note that in fast-growing microalgae mass cultures, the increase in biomass density inevitably results in self-shading, and subsequent growth limitation (Masojídek et al. 2011b).

If we consider $\mathrm{rETR}_{\max }$ and $\mathrm{E}_{\mathrm{K}}$ (Figs. 4B, 5A) vs. nutrient content in the media (Fig. 1S), one can illustrate that the primary limitation of the growth in our trials was caused by the decreased light availability due to increased cell density and not by nutrient limitation. Here, it is important to emphasize that on Day 6, the values of rETR $_{\max }$ (Fig. $4 B$ ) were still higher in higher-irradiance culture
(Trial B) than those in the lower-irradiance culture (Trial A). However, on Day 9, the trend was inevitably reversed as the $\mathrm{rETR}_{\max }$ values were by about $33 \%$ lower in Trial B than those in Trial A (Fig. 4B); this coincided with the decelerating phase of the growth curve (Fig. 2) when biomass density reached about $5 \mathrm{~g} \mathrm{~L}^{-1}$ in Trial B although there were still enough nutrients $(28-48 \%$ of the initial amount, respectively; Fig. S1B). On Day 9, the decrease of $E_{K}$ also indicated that the denser culture in Trial B was acclimated to more than $30 \%$ lower irradiance $\left[\mathrm{E}_{\mathrm{K}}=266 \mu \mathrm{mol}\right.$ (photon) $\left.\mathrm{m}^{-2} \mathrm{~s}^{-1}\right]$ as compared to the thinner culture $\left[\mathrm{E}_{\mathrm{K}}=400 \mu \mathrm{mol}\left(\right.\right.$ photon) $\left.\mathrm{m}^{-2} \mathrm{~s}^{-1}\right]$ (Fig. $5 A$ ). These results suggested that the photosynthetic activity was limited by low cell irradiance when culture became dense (Masojídek et al. 2011a, Richmond 2013).

In our opinion the variables $\mathrm{F}_{\mathrm{v}} / \mathrm{F}_{\mathrm{m}}$ and $\mathrm{rETR}$ may express different degree of constrains - 'distress' when $\mathrm{F}_{\mathrm{v}} / \mathrm{F}_{\mathrm{m}}$ changes dramatically (photoinhibition) and functional downregulation, 'eustress' when the rETR values decrease. To say it in other words, the cultures in the presented experiments were quickly acclimated and benefited from higher irradiance as seen from high growth rate, but in the later phase of the trials they suffered lowlight acclimation.

It is shown here that the primary reason of the downregulation of photosynthetic activity in these trials was the significant increase in biomass density that prevents the light penetration to cells causing low-light adaptation and the depletion of the nutrients in the medium might be partially limiting in the final phase of the trial (Fig. $3 B$ and $4 B$ vs. Trial B in Fig. 1S).

Conclusion: In the tested PBR, we used high-intensity/ short light-path internal illumination by the LED light sources which were submerged directly into culture. This PBR makes possible to adjust a wide range of culture conditions for growth of microalgae monocultures, e.g. irradiance intensity and temperature as well as efficient $\mathrm{CO}_{2} / \mathrm{O}_{2}$ exchange, high cell turbulence, and good protection against contamination. The correlation between photosynthetic activity and growth kinetics can be used when evaluating optimal cultivation regime for microalgae strains.

Chlorophyll fluorescence variables resulting from saturating pulse analysis of fluorescence quenching and fast induction kinetics were used as a tool to measure photosynthetic activity. The knowledge of physiological responses of specific microalgae strain(s) and the estimation of relevant marker variables and set-up of measuring protocols in such small-scale PBRs can be used for scale-up, i.e. the design and optimisation of large-scale commercial plants. Here, we studied the situation when the seed culture is transferred from laboratory and exposed to ambient irradiance outdoors.

The photobioreactor LED-PBR-10 described here was used to test the construction of a pilot-scale 100-L photobioreactor, LED-PBR-100 (Sergejevová et al. 2015) with one central LED light source which is now being used for production of sensitive strains or seed cultures for larger systems. Another step of scale-up has been a 
1,000-L photobioreactor with flat LED-panels submerged in the culture.

If we consider practical use of such photobioreactors with internal illumination in larger-scale systems for biomass or bioactive compound production, then these should be operated in semibatch or continuous mode when a part of biomass is regularly harvested at the upper part of the exponential phase. At present, we are using this scheme to produce microalgae biomass containing particular bioactive compounds in various stages of culture development.

\section{References}

Acién F.G., Molina E., Reis A. et al.: Photobioreactors for the production of microalgae. - In: Gonzalez-Fernandez C., Muñoz R. (ed.): Microalgae-based Biofuels and Bioproducts. From Feedstock Cultivation to End-products. Pp. 1-44. Woodland Publishing, Elsevier Science \& Technology, Cambridge, UK 2017.

An J.-Y., Kim B.-W: Biological desulfurization in an opticalfiber photobioreactor using an automatic sunlight collection system. - J. Biotechnol. 80: 35-44, 2000.

Babaei A., Ranglová K., Malapascua J.R., Masojídek J.: The synergistic effect of Selenium (selenite, $-\mathrm{SeO}_{3}{ }^{2-}$ ) dose and irradiance intensity in Chlorella cultures. - AMB Express 7: $56,2017$.

Bischof K., Gómez I., Molis M. et al.: Ultraviolet radiation shapes seaweed communities. - Rev. Environ. Sci. Bio. 5: 141-166, 2006.

Carvalho A.P., Meireles L.A., Malcata F.X.: Microalgal reactors: a review of enclosed system designs and performances. Biotechnol. Progr. 22: 1490-506, 2006.

Chen C.-Y., Chang J.-S.: Enhancing phototropic hydrogen production by solid-carrier assisted fermentation and internal optical-fiber illumination. - Process Biochem. 41: 20412049, 2006.

Chen C.-Y., Lee C.-M., Chang J.-S.: Feasibility study on bioreactor strategies for enhanced photohydrogen production from Rhodopseudomonas palustris WP3-5 using opticalfiber-assisted illumination systems. - Int. J. Hydrogen Energ. 31: 2345-2355, 2006a.

Chen C.-Y., Lee C.-M., Chang J.-S.: Hydrogen production by indigenous photosynthetic bacterium Rhodopseudomonas palustris WP3-5 using optical fiber-illuminating photobioreactors. - Biochem. Eng. J. 32: 33-42, 2006 b.

Chen C.-Y., Saratale G.D., Lee C.-M. et al.: Phototrophic hydrogen production. - Int. J. Hydrogen Energ. 33: 68866895, 2008.

Chiang C.L., Lee C.M., Chen P.-C.: Utilization of cyanobacteria Anabaena sp. CH1 in biological carbon dioxide mitigation processes. - Bioresource Technol. 102: 5400-5405, 2011.

Choi Y.E., Yun Y.S., Park J.M.: Multistage operation of airlift photobioreactor for increased production of astaxanthin from Haematococcus pluvialis. - J. Microb. Biotechnol. 21: 10811087, 2011.

Csögör Z., Kiessling B., Perner I. et al.: Growth and product formation of Porphyridium purpureum. - J. Appl. Phycol. 13: 317-324, 2001.

Cuaresma M., Janssen M., Vílchez C., Wijffels R.H.: Productivity of Chlorella sorokiana in a short light-path (SLP) panel photobioreactor under high irradiance. - Biotechnol. Bioeng. 104: 352-359, 2009.

Eilers P.H.C., Peeters J.C.H.: A model for the relationship between light intensity and the rate of photosynthesis in phytoplankton. - Ecol. Model. 42: 199-215, 1988.

Enriquez S., Borowitzka M.A.: The use of the fluorescence signal in studies of seagrasses and macroalgae. - In: Suggett D.J., Práśil O, Borowitzka M.A. (ed.): Chlorophyll a Fluorescence in Aquatic Sciences: Methods and Applications. Developments in Applied Phycology, Vol. 4. Pp. 187-208. Springer, Dordrecht 2010.

Figueroa F., Mercado J., Jiménez C. et al.: Relationship between bio-optical characteristics and photoinhibition of phytoplankton. - Aquat. Bot. 59: 237-251, 1997.

Figueroa F., Jerez C., Korbee N.: Use of in vivo chlorophyll fluorescence to estimate photosynthetic activity and biomass productivity in microalgae grown in different culture systems. - Lat. Am. J. Aquat. Res. 41: 801-819, 2013.

Gordon J.M.: Tailoring optical systems to optimized photobioreactors. - Int. J. Hydrogen Energ. 27: 1175-1184, 2002.

Grobbelaar J., Nedbal L., Tichý V.: Influence of high frequency light/dark fluctuations on photosynthetic characteristics of microalgae photoacclimated to different light intensities and implications for mass algal cultivation. - J. Appl. Phycol. 8: 335-343, 1996.

Havlik I., Lindner P., Scheper T., Reardon K.F.: On-line monitoring of large cultivations of microalgae and cyanobacteria. - Trends Biotechnol. 31: 406-414, 2013.

Hirata S., Hayashitani M., Taya M., Tone S.: Carbon dioxide fixation in batch culture of Chlorella sp. using a photobioreactor with a sunlight-collecting device. - J. Biosci. Bioeng. 81: 470-472, 1996.

Hofstraat J.W., Peeters J.C., Snel J.F.H., Geel C.: Simple determination of photosynthetic efficiency and photoinhibition of Dunaliella tertiolecta by saturating pulse measurements. Mar. Ecol. Prog. Ser. 103: 187-196, 1994.

Jacobi A., Steinweg C., Rosello-Sastre R., Poste C.: Advanced photobioreactor LED illumination system: scale-down approach to study microalgal growth kinetics. - Eng. Life Sci. 12: 621-630, 2012.

Janssen M., de Bresser L., Baijens T. et al.: Scale-up aspects of photobioreactors: effects of mixing-induced light/dark cycles. - J. Appl. Phycol. 12: 225-237, 2000.

Kromkamp J.C., Barranguet C., Peene J.: Determintaion of microphytobenthos PSII quantum efficiency and photosynthetic activity by means of variable chlorophyll fluorescence. - Mar. Ecol. Prog. Ser. 162: 45-55, 1998.

Kromkamp J.C., Forster R.M.: The use of variable fluorescence measurements in aquatic ecosystems: differences between multiple and single turnover measuring protocols and suggested terminology. - Eur. J. Phycol. 38: 103-112, 2003.

Lee C.-G., Palsson B.O.: High-density algal photobioreactors using light-emitting diodes. - Biotechnol. Bioeng. 44: 11611167, 1994.

Lee C.G., Palson B.O.: Light-emitting diode based algal photobioreactor with external gas exchange. - J. Ferment. Bioeng. 79: 257-263, 1995.

Malapascua J.R., Jerez C., Sergejevová M. et al.: Photosynthesis monitoring to optimize growth of microalgal mass cultures: application of chlorophyll fluorescence techniques. - Aquat. Biol. 22: 123-140, 2014.

Masojídek J., Kopecký J., Koblížek M., Torzillo G.: The xanthophyll cycle in green algae (Chlorophyta): its role in the photosynthetic apparatus. - Plant Biol. 6: 342-349, 2004.

Masojídek J., Torzillo G.: Mass cultivation of freshwater microalgae. - In: Jorgensen S.E., Fath B. (ed.): Encyclopaedia of Ecology. Pp. 2226-2235. Elsevier, Oxford 2008.

Masojídek J., Vonshak A., Torzillo G.: Chlorophyll fluorescence application in microalgal mass cultures. - In: Suggett D.J., Prášil O., Borowitzka M.A. (ed.): Chlorophyll a Fluorescence 
in Aquatic Sciences: Methods and Applications. Pp. 277-292. Springer, Dordrecht 2011a.

Masojídek J., Kopecký J., Giannelli L., Torzillo G.: Productivity correlated to photobiochemical performance of Chlorella mass cultures grown outdoors in thin-layer cascades. - J. Ind. Microbiol. Biot. 38: 307-317, 2011 b.

Masojídek J., Sergejevová M., Malapascua J.R., Kopecký J.: Thin-layer systems for mass cultivation of microalgae: flat panels and sloping cascades. - In: Bajpai R., Prokop A., Zappi M. (ed.): Algal Biorefinery, Vol. 2: Products and Refinery Design. Pp. 237-261, Springer International Publishing, Switzerland 2015.

Maxwell K., Johnson G.N.: Chlorophyll fluorescence - a practical guide. - J. Exp. Bot. 51: 659-668, 2000.

Nedbal L., Tichy V., Xiong F.H., Grobbelaar J.U.: Microscopic green algae and cyanobacteria in high-frequency intermittent light. - J. Appl. Phycol. 8: 325-333, 1996.

Nedbal L., Trtílek M., Červený J. et al.: A photobioreactor system for precision cultivation of photoautotrophic microorganisms and for high-content analysis of suspension dynamics. Biotechnol. Bioeng. 100: 902-910, 2012.

Obata M., Tatsuki T., Taguchi S.: Using chlorophyll fluorescence to monitor yields of microalgal production. - J. Appl. Phycol. 21: 315-319, 2009.

Ogbonna J.C., Yada H., Masui H., Tanaka H.: A novel internally illuminated stirred tank photobioreactor for large-scale cultivation of photosynthetic cells. - J. Ferment. Bioeng. 82: 61-67, 1996.

Ogbonna J.C., Soejima T., Tanaka H.: An integrated solar and artificial light system for internal illumination of photobioreactors. - J. Biotechnol. 70: 289-297, 1999.

Phillips J.N., Myers J.: Growth rate of chlorella in flashing light. - Plant Physiol. 29:152-161, 1954.

Pulz O., Broneske J., Waldeck P.: IGV GmbH experience report, industrial production of microalgae under controlled conditions: innovative prospects. - In: Richmond A., Hu Q. (ed.): Handbook of Microalgal Culture: Applied Phycology and Biotechnology, $2^{\text {nd }}$ edition. Pp. 445-460. John Wiley \& Sons, Oxford 2013.

Radmer R.J.: Using a lamp having a higher intensity and efficiency. - US patent 4952511 B, 1989

Ralph P.J., Gademann R.: Rapid light curves: A powerful tool to assess photosynthetic activity. - Aquat. Bot. 82: 222-237, 2005.

Richmond A.: Biological principles of mass cultivation of photoautotrophic microalgae. - In: Richmond A., Hu Q. (ed.): Handbook of Microalgal Culture: Applied Phycology and Biotechnology $2^{\text {nd }}$ edition. Pp. 171-204. John Wiley \& Sons, Oxford 2013.

Ritchie R.J.: Fitting light saturation curves measured using modulated fluorometry. - Photosynth. Res. 96: 201-215, 2008.

Schreiber U., Schliwa U., Bilger W.: Continuous recording of photochemical and nonphotochemical fluorescence quenching with a new type of modulation fluorimeter. - Photosynth. Res. 10: $51-62,1986$.

Sergejevová M., Malapascua J.R., Kopecký J., Masojídek J.: Photobioreactors with internal illumination. - In: Prokop A., Bajpai R., Zappi M. (ed.): Algal Biorefineries: Products and Refinery Design. Pp. 213-236. Springer International Publishing, Switzerland 2015.

Šetlík I., Berková E., Doucha J. et al.: The coupling of synthetic and reproduction processes in Scenedesmus quadricauda. Arch. Hydrobiol. 7: 172-213, 1972.

Stirbet A., Govindjee: On the relation of the Kautsky effect (chlorophyll $a$ fluorescence induction) and photosystem II: basics and applications of the OJIP fluorescence transient. - J. Photoch. Photobio. B 104: 236-257, 2011.

Strasser R.J., Srivastava A., Govindjee: Polyphasic chlorophyll $a$ fluorescence transient in plants and cyanobacteria. Photochem. Photobiol. 61: 33-42, 1995.

Strasser R., Tsimilli-Michael M., Srivastava A.: Analysis of the chlorophyll $a$ fluorescence transients. - In: Papageorgiou G.C., Govindjee (ed.): Chlorophyll $a$ Fluorescence: A Signature of Photosynthesis. Pp. 321-362. Springer, Dordrecht 2004.

Suh I.S., Lee S.B.: Cultivation of a cyanobacterium in an internally radiating air-lift photobioreactor. - J. Appl. Phycol. 13: 381-388, 2001.

Torzillo G., Accolla P., Pinzani E., Masojídek J.: In situ monitoring of chlorophyll fluorescence to assess the synergistic effect of low temperature and high irradiance stresses in Spirulina cultures grown outdoors in photobioreactors. - J. Appl. Phycol. 8: 283-291, 1996.

Torzillo G., Bernardini P., Masojídek J.: On-line monitoring of chlorophyll fluorescence to assess the extent of photoinhibition of photosynthesis induced by high oxygen concentration and low temperature and its effect on the productivity of outdoor cultures of Spirulina platensis (Cyanobacteria). - J. Phycol. 34: 504-510, 1998.

Tredici M.: Mass production of microalgae: photobioreactors. - In: Richmond A. (ed.): Handbook of Microalgal Mass Cultures. Pp. 178-214. Blackwell Science, Oxford 2004.

van Kooten O., Snel J.F.H.: The use of chlorophyll fluorescence nomenclature in plant stress physiology. - Photosynth. Res. 25: 147-150, 1990.

Vonshak A., Torzillo G., Tomaseli L.: Use of chlorophyll fluorescence to estimate the effect of photoinhibition in outdoor cultures of Spirulina platensis. - J. Appl. Phycol. 6: 31-34, 1994.

Walker D.A.: Measurement of oxygen and chlorophyll fluorescence. - In: Cooms J., Hall D.O., Long S.P., Scurlock J.M.O. (ed.): Techniques in Bioproductivity and Photosynthesis, $2^{\text {nd }}$ edition. Pp. 95-98. Pergamon Press, Oxford 1985.

Wang S.-K., Stiles A.R., Guo C., Liu C.-Z.: Microalgae cultivation in photobioreactors: an overview of light characteristics. Eng. Life Sci. 14: 550-559, 2014.

Wellburn A.R.: The spectral determination of chlorophylls $a$ and $b$, as well as total carotenoids, using various solvents with spectrophotometers of different resolution. - J. Plant Physiol. 144: 307-313, 1994.

White S., Anandraj A., Bux F.: PAM fluorometry as a tool to assess microalgal nutrient stress and monitor cellular neutral lipids. - Biotechnol. Resour. 102: 1675-1682, 2011.

Yam F.K., Hassan Z.: Innovative advances in LED technology. Microelectron J. 36: 129-137, 2005.

Zachleder V., Šetlík I.: Effect of irradiance on the course of RNA synthesis in the cell cycle of Scenedesmus quadricauda. Biol. Plantarum 24: 341-353, 1982.

Zarmi Y., Bel G., Aflalo C.: Theoretical analysis of culture growth in flat-plate bioreactors: the essential role of timescales. - In: Richmond A., Hu Q. (ed.): Handbook of Microalgal Culture: Applied Phycology and Biotechnology, $2^{\text {nd }}$ edition. Pp. 205224. John Wiley \& Sons, Oxford 2013.

Zittelli G.C., Biondi N., Rodolfi L., Tredici M.R.: Photobioreactors for mass production of microalgae. - In: Richmond A., Hu Q. (ed.): Handbook of Microalgal Culture: Applied Phycology and Biotechnology. 2nd ed. Pp. 225-266. John Wiley \& Sons, Oxford 2013.

(C) The authors. This is an open access article distributed under the terms of the Creative Commons BY-NC-ND Licence. 